\title{
Relationships of pest grasshopper populations in Alberta, Canada to soil moisture and climate variables
}

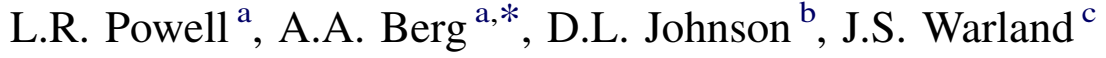 \\ ${ }^{a}$ Department of Geography, University of Guelph, Guelph, Ont., Canada N1G 2W1 \\ ${ }^{\mathrm{b}}$ Department of Geography, University of Lethbridge, Lethbridge, Alta., Canada T1K $3 M 4$ \\ ${ }^{\mathrm{c}}$ Department of Land Resource Science, University of Guelph, Guelph, Ont., Canada N1G 2W1
}

Received 7 July 2006; received in revised form 18 January 2007; accepted 31 January 2007

\begin{abstract}
This study examines regional relationships between climate, soil moisture, and pest grasshopper populations in Alberta. The objectives of this study are two-fold: (a) to investigate soil moisture as a potential predictor of pest grasshopper populations; and (b) to determine whether or not relationships between pest grasshopper populations and weather and soil moisture exist at the regional scale. Simple correlations and a modified chi-squared procedure are employed to investigate these relationships. Fall and spring soil moisture conditions appear to have some predictive capacity, showing strong associations to grasshopper abundance. Furthermore, regional relationships between temperature and soil moisture and the pest grasshopper populations are also identified. These relationships appear far stronger relative to low grasshopper populations, suggesting that population declines are easier to predict than outbreaks. Cool, wet weather in the spring and warm, dry weather in the fall and early winter are strongly associated with low populations.
\end{abstract}

(C) 2007 Elsevier B.V. All rights reserved.

Keywords: Grasshopper abundance; Soil moisture and climate; Alberta

\section{Introduction}

Drought, plant or livestock disease and pest infestations have moderate to severe impacts on agricultural productivity throughout the Canadian Prairies. These challenges present serious problems not only for the individual farmer, but also to provincial and national economies. While drought can reduce overall income of an individual farmer, pest infestations represent an immediate concern because they can devastate a crop in a matter of days. In the province of Alberta, Canada, annual predictions of the risk of outbreak of pest grasshopper

\footnotetext{
* Corresponding author. Tel.: +1 519824 4120; fax: +1 5198372940 .

E-mail address: aberg@uoguelph.ca (A.A. Berg).
}

species are generated based on the previous year's populations, and to a lesser extent on other variables such as the condition of vegetation and the spring weather. The goal of these predictions is to provide a qualitative risk assessment to farmers, government advisors and pest control managers with estimates of abundance and probable timing. Preemptive mitigation efforts have been shown to be more successful and less expensive than controlling populations once the grasshoppers have dispersed, so accurate predictions can lead to more effective and efficient pest management strategies (Zimmerman et al., 2004).

The role of temperature in relation to grasshopper growth and development has been studied in detail (Parker, 1930; MacCarthy, 1956; Pickford, 1966; Fisher, 1994), producing growth rate functions according to temperature (Stinner et al., 1974; Lactin et al., 1995). 
Above a minimum temperature, the growth rate increases non-linearly up to a maximum temperature, beyond which no development occurs. The minimum and maximum temperatures are species-specific, but the shape of the function remains similar for most species of grasshoppers.

The role of precipitation has also been examined, but these studies have been confined to statistical investigations of field data (MacCarthy, 1956; Edwards, 1960, 1964; Gage and Mukerji, 1977; Johnson and Worobec, 1988). While many of these studies indicate that precipitation is inversely correlated with pest grasshopper populations, particularly during the spring (i.e., high precipitation levels reduce potential grasshopper populations), considerable variability is reported regarding the timing of precipitation-population relationships. Gage and Mukerji (1977) and Capinera and Horton (1989) found only weak associations between grasshopper populations and precipitation, and required the introduction of a drought index (heat/precipitation ratios) to establish links between precipitation and grasshopper populations.

Some of the difficulty in assessing the precipitationpopulation relationships may be due to having no measure for the actual amount of water available in the grasshopper's environment, most notably the soil moisture state. Several arguments for including soil moisture as a potential explanatory variable can be made. The soil moisture status is a function of a wide variety of factors which affect grasshopper abundance, such as precipitation (e.g. Edwards, 1960, 1964; Johnson and Worobec, 1988), soil texture and composition (Johnson, 1989a,b), slope and aspect (Coxwell and Bock, 1995), soil depth (Schell and Lockwood, 1997), snow cover and the integrated impacts of evaporative effects (humidity, wind speed, air temperature and radiation). Moreover, soil moisture represents the actual amount of water available to the grasshopper or embryo (Uvarov, 1966), as well as to the plants upon which grasshoppers feed.

The absence of soil moisture in studies of regional grasshopper population dynamics has largely been the result of an inability to acquire consistent and reliable soil moisture data over an extended period of time. Field soil moisture observations are generally expensive and time-consuming to acquire, and often only cover a small geographic area. To overcome these disadvantages, advances in hydrologic modeling, remote sensing, and data assimilation techniques have been employed as a means to acquire information about the soil moisture status. In particular, soil moisture observations from space-based microwave remote sensing platforms have been shown to be useful in providing estimates of surface soil moisture (top few centimeters). Currently, only a small number of satellites are adequate for estimating soil moisture, including the Advanced Microwave Scanning Radiometer (AMSR-E) (Njoku et al., 2003) and in the very near future observations will be available from the Soil Moisture and Ocean Salinity satellite mission (Kerr et al., 2001).

As these methods of soil moisture measurement are improved upon, the inclusion of soil moisture into studies of grasshopper population dynamics, and ecological processes in general, will increase. The main goal of this study is to evaluate the relationships of historical grasshopper populations to modeled soil moisture and observed precipitation and temperature. The observed associations will be useful in directing the development of future mechanistic or multivariate statistical models, and for predicting impacts of possible climate trends and variability.

\section{Data and methods}

In the Canadian Prairies and the Northern Great Plains, there are four grasshoppers species which are considered to be recurring serious pests of agriculture: the clear-winged grasshopper (Camnula pellucida), the migratory grasshopper (Melanoplus sanguinipes), the two-striped grasshopper (Melanoplus bivittatus), and the Packard's grasshopper (Melanoplus packardii). These four species (particularly the first three mentioned) comprise the majority of grasshopper populations in Canada. An outbreak is triggered by a population increase by these species, and these are the principal species that are monitored in late-summer surveys of breeding populations (Johnson, 1989a,b). From these annual surveys a data set from 1979 to 1999 was used in this analysis. The individual data points representing late-season grasshopper counts (breeding population density) were input into a Geographic Information System (ESRI's ArcView 3.2). Overlaid on top of the data points was a layer containing individual stream catchments defined by the USGS HYDRO1k (Verdin and Verdin, 1999) (illustrated in Fig. 1). Grasshopper counts contained in the individual catchment polygons were averaged, such that each catchment polygon was assigned one population value per year, with the constraint that a minimum of three counts occurred within the individual catchment for each year. The interpolation of grasshopper counts to the level of individual catchments was completed to allow for matching the grasshopper counts to the resolution of the land surface hydrological model used to produce soil 


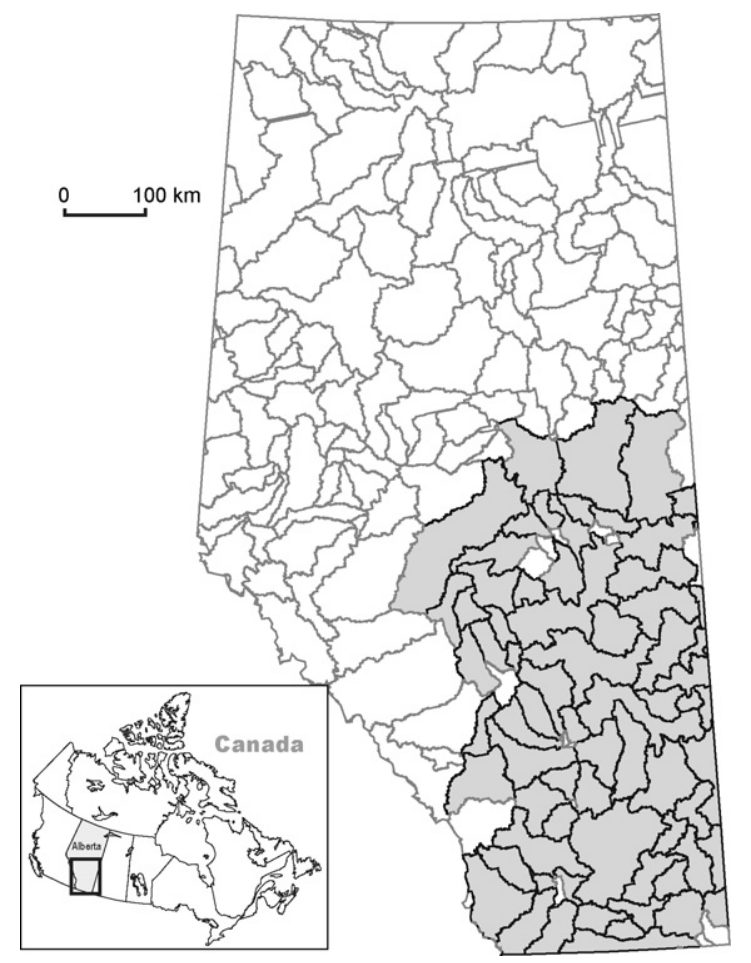

Fig. 1. Catchments in Alberta as defined in the NASA Catchment land surface model. The catchments highlighted are those used in this study.

moisture estimates for the basin (see discussion about the model below).

The daily temperature and precipitation values were derived from a gridded temperature and precipitation data set created for the Prairie region from historical weather station records provided by Environment Canada. The individual station data were interpolated to a standard $1 / 8$ of a degree grid using an inverse distances squares interpolation scheme. Daily grids for the period 1979-1999 were created for daily minimum and maximum temperatures and precipitation. From this gridded data set catchment average daily maximum and minimum temperature and precipitation were determined following the strategy described above.

A daily soil moisture estimate was calculated using the NASA Catchment land surface model (Ducharne et al., 2000; Koster et al., 2000). The catchment model uses atmospheric forcing [short- and longwave downwelling radiation, convective and total precipitation, 2$\mathrm{m}$ air and dew point temperatures, $10 \mathrm{~m}$ wind speed, and surface pressure as described in Berg et al. (2003, 2005)], with surface parameter descriptions (vegetation type, height, greenness, and leaf area index, roughness length at surface, albedo, and soil hydrological properties) to derive land surface energy and water budgets including an estimate of the soil moisture status. Previous research by Berg et al. (2003) and Reichle et al. (2004) demonstrate statistically significant relationships between the catchment land surface model and soil moisture observations. The resolution of the modeling framework follows the hydrological catchments of Verdin and Verdin (1999), which necessitated the interpolation of grasshopper and station observations to the identical catchment resolution. Thus, each catchment had a single value for daily minimum and maximum temperatures, precipitation, and surface and root zone soil moisture together with the yearly grasshopper density survey information.

\subsection{Correlations}

Numerous researchers have attempted to establish relationships between grasshopper populations and weather using correlation and regression methods at the field scale (MacCarthy, 1956; Edwards, 1960; Gage and Mukerji, 1977; Capinera and Horton, 1989; Fielding and Brusven, 1990). In this study, daily climate variables were averaged to mean monthly values, to allow for comparison to past studies and to evaluate if relationships observed at field scales are also observable at the regional scale adopted in this analysis. Pearson correlations were evaluated between monthly mean temperature, precipitation, root zone and surface soil moisture and the mean grasshopper density for each catchment for the time period 1979-1999. For each climate and soil moisture variable, 14 maps of the correlation coefficients were completed, spanning the time period of July of the previous year to August of the year that the grasshopper count was completed. For each of the 14 correlation maps we identified the total number of catchments with statistically significant correlations $(p<0.05)$ between the grasshopper populations and the weather and soil moisture variables.

To address the problems of multiplicity and spatial autocorrelation in the climate and soil moisture data, a Monte Carlo simulation was conducted following Livezey and Chen (1983). In this method, the grasshopper population densities were randomly re-sampled thus shifting the year-to-year correspondence of the grasshopper density, climate and soil moisture variables. In this technique the spatial patterns of climate and grasshopper densities are not altered, however the year-to-year correspondence is randomly reshuffled. The correlations between the shuffled grasshopper densities, climate and soil moisture were then recalculated. The reshuffling and calculation process was repeated 5000 times and the average number of 
catchments demonstrating statistical significance calculated. In this study, we assume statically significant relationships between the grasshopper density and the climate or soil moisture variable (field significance) only if the number of catchments reporting significant correlations for a given month exceeds the average value determined in the Monte Carlo analysis.

\subsection{Iterative chi-squared technique}

The iterative chi-squared technique, developed by Caprio (1966), was designed as means to investigate first-approximations of relationships between discreet biological data and weather. This technique was originally developed to compare crop yield records with climate records. It has been applied to apples and grapes in British Columbia (Caprio and Quamme, 1999, 2002) and vegetable yields in Ontario (McKeown et al., 2005). An important feature of the Caprio (1966) method is the identification of both the timing and direction (either positive or negative) of a relationship observed between weather and the biological phenomena investigated. The reader is referred to Caprio and Quamme $(1999,2002)$ and McKeown et al. (2005) for recent reviews of this method, a brief description of how this method was adopted for use in our analysis is presented below.

In this study and in each of the catchments, the variables (daily minimum temperature, maximum temperature, root zone and surface soil moisture) are each separated into bins. For each variable, two incrementing and two decrementing cumulative frequency tables are created of the number of occurrences of the daily climate values over a 3 -week period, one of each for the extreme years (either low or high populations as determined by the top and bottom quartiles of the population time series), and one of each for the average years (the remaining years in the time series). Over this 3-week window, a chi-squared statistic is calculated for each bin between the two incrementing frequency tables (high/low years versus average years), or the two decrementing frequency tables. Where the chi-squared statistic is greater than 7 or less than -7 $(p<0.01)$ in any bin, it can be concluded that a significant difference exists in climate conditions in extreme years versus average years.

As it was originally developed, the iterative chisquare technique produces as output a threshold value for maximum significance. Significance is interpreted as an excess of deficit of days above or below the threshold. For example, in McKeown et al. (2005) low yields of cabbage were found to correlate with an excess number of days (over the 3-week window of the analysis) with maximum temperatures above $32{ }^{\circ} \mathrm{C}$ in August. Because of the spatial component of this study, defining a single threshold value across the entire domain was not considered meaningful for the purpose of this study, which was to establish relationships between climate and soil variables with grasshopper outbreaks. This output from the iterative chi-square analysis was ignored in this study.

The original formulation of the iterative chi-square analysis also differentiates between an excess of days greater than (less than) a threshold and a deficit of days below (above) a threshold. For example, hot weather may be shown by an excess of days greater than a threshold, or by a deficit of days below a threshold. In this study, these two conditions were found to strongly correlate, and so the distinction was not made. Instead, conditions describing, for example, hot weather were treated as the same class. In the example above, deficit (of days below a threshold) or excess (of days above a threshold) would not be distinguished, both cases would be treated as above-average temperature.

A Monte Carlo analysis similar to that described above is used to evaluate the field significance (Livezey and Chen, 1983), whereby the time series of grasshopper densities was randomly shuffled and the chisquared analysis completed against the randomly selected population density data. This procedure was repeated 5000 times on the re-sampled data. If the number of catchments reporting significant associations for a given 3-week period exceeded the value determined by the Monte Carlo simulation, then that week would be considered statistically significant (field significance).

Grasshoppers may respond differently to their environmental conditions at different times in their growth and development cycles (Uvarov, 1966, 1977). In order to ensure that we could adequately compare the results between catchments, the output was standardized such that each week represents a similar level of phenological development throughout all of the catchments in the study area. The standardized reference week was calculated by inputting temperature into growth curves established by Lactin et al. (1995) and incrementing the estimated percentage of development completed each day until it reached $100 \%$. Thus, the weeks of the year are standardized across the catchments to represent phenological development which will vary across the catchments according to temperature. Week numbers (the numbers across the top of each of the figures) were used to reference the approximate timing of relationships. Week numbers can 
be translated to general times of the year (within \pm 3 to 4 weeks), where week 1 is approximately late July or early August of the previous year, and week 51 occurs approximately around late May or early June.

Precipitation was omitted from the following analysis because of the incompatibility of the precipitation data with the chi-squared analysis particularly in a region as dry as the Canadian prairies. The number of days of zero precipitation creates a bin in the cumulative frequency tables which has a very high number of days with no precipitation for both the extreme years and the average years. In order for there to be a statistically significant difference, the total number of days of zero precipitation must be much higher or lower in average years than in extreme years. Increasing the size of the bins to include more days reduces the usefulness of this analysis.

\section{Results and discussion}

In the following section we describe the relationships between weather parameters (temperature, precipitation), soil moisture and the sampled grasshopper population densities. In the discussion below, we first address the correlation relationships between the observed grasshopper densities with climate observations of temperature, precipitation and soil moisture. Numerous studies have focused on the statistical relationships among weather and grasshopper popula- tion densities at the field scale (MacCarthy, 1956; Edwards, 1960; Gage and Mukerji, 1977; Capinera and Horton, 1989; Fielding and Brusven, 1990). In the discussion below we will evaluate these simple correlation relationships at regional scales, and investigate the importance of soil moisture for inclusion in predictive relationships for population densities. In the later sections we further explore these relationships using the iterative chi-squared technique described above which allows us to explore these relationships with greater temporal resolution. Investigations into the importance of the spatial patterns of the relationships identified will be the focus of a future analysis.

\subsection{Temperature-grasshopper correlations}

In Fig. 2 positive (Fig. 2a) and negative (Fig. 2b) correlations between temperature and grasshopper populations are plotted across the 70 catchments in the study area. The bars indicate the percentage of the 70 catchments exhibiting statistically significant relationships between temperature and subsequent population density. The black bars indicate the Monte Carlo threshold for statistical significance across the entire study area for the month. Where grey bars are present, a statistically significant number of catchments exhibit statistically significant correlations over the study area $(p<0.05)$.
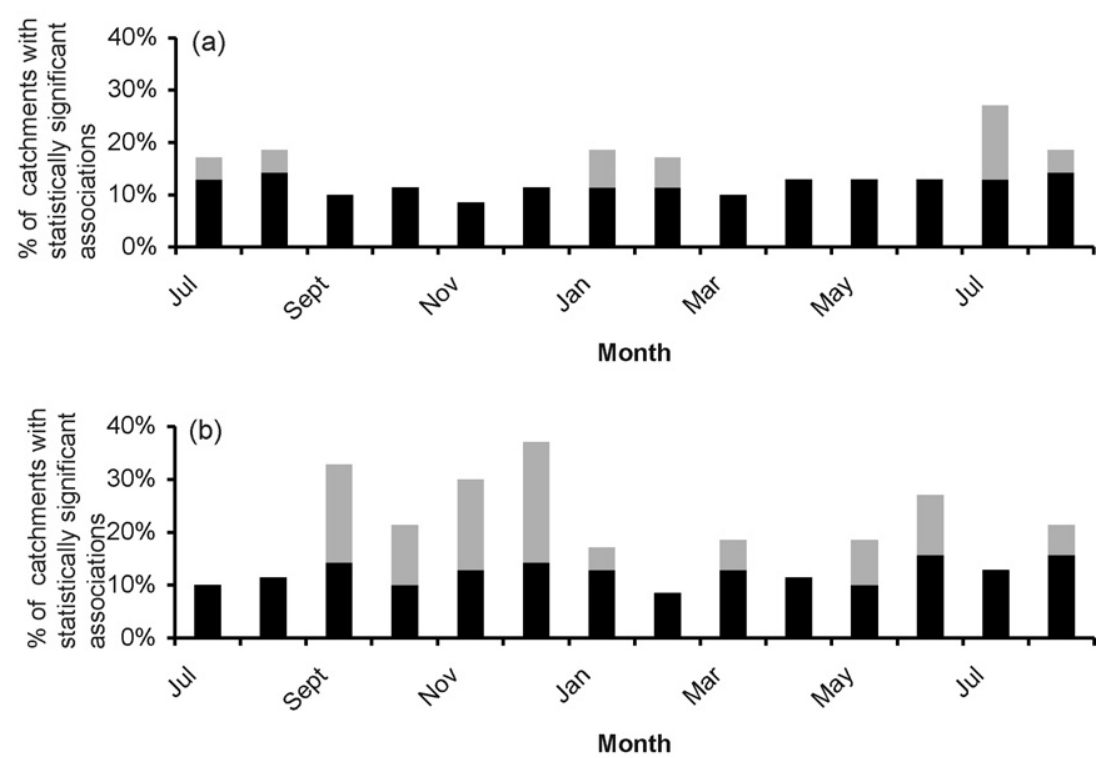

Fig. 2. Summary of the results for the temperature correlations: (a) percentage of catchments reporting significant positive correlations and (b) percentage of catchments reporting significant negative correlations. Grey bars represent the actual number of catchments reporting significance, black bars represent the threshold required for field significance as determined in the Monte Carlo analysis. 
Negative correlations between mean monthly temperature and subsequent populations are observed over the late fall to early winter months, with September, October, November, and December all showing between $21 \%$ and $40 \%$ of catchments reporting statistically significant negative correlations (where $10-15 \%$ was required for field significance). Negative correlations were also observed in May and June, with $18 \%$ and 27\% of catchments reporting significant negative correlations, respectively. July and August show a significant positive relationship ( $>18 \%$ of catchments), although August also had a significant number of catchments also reporting a negative relationship. The problem of a significant number of catchments reporting both positive and negative correlations suggests that the signal is confounded by other variables.

The negative correlations between mean monthly temperature and grasshopper populations in the late fall-early winter months (September-December) are similar to results to those of past studies, such as Fielding and Brusven (1990), whose study of historical grasshopper populations in Idaho showed a significant negative correlation in November, December, and January. They hypothesize that low temperatures during the early winter months freezes the soil, preventing moisture from leaving the soil through evaporation. When the soil thaws in March or April, that extra moisture is then available for young spring grasses, a nutritious food source for grasshopper nymphs.
However, the physical mechanism that guides this association is unknown.

\subsection{Precipitation-grasshopper population correlations}

Fig. 3 illustrates the associations between precipitation and grasshopper populations plotted over all 70 catchments. August in the previous year showed a significant negative correlation (23\% of catchments). A strong positive relationship was observed for September (30\% of catchments), followed by weaker but still significant positive relationships between October and December (approximately 20\% of catchments). The signal is less clear during the spring and summer months (April-August of the current year), where precipitation is subject to higher levels of evaporative and runoff losses than in the winter.

Similar to the temperature correlations, the field significance in the correlations between mean monthly precipitation and grasshopper populations are observed in the months of September through December, although this relationship is much weaker than those observed for temperature over the same time period. Similar associations were established by Fielding and Brusven (1990), who found a significant correlation between precipitation and grasshopper densities in November. These results further support the hypothesis of Fielding and Brusven (1990) given the negative correlations with temperature
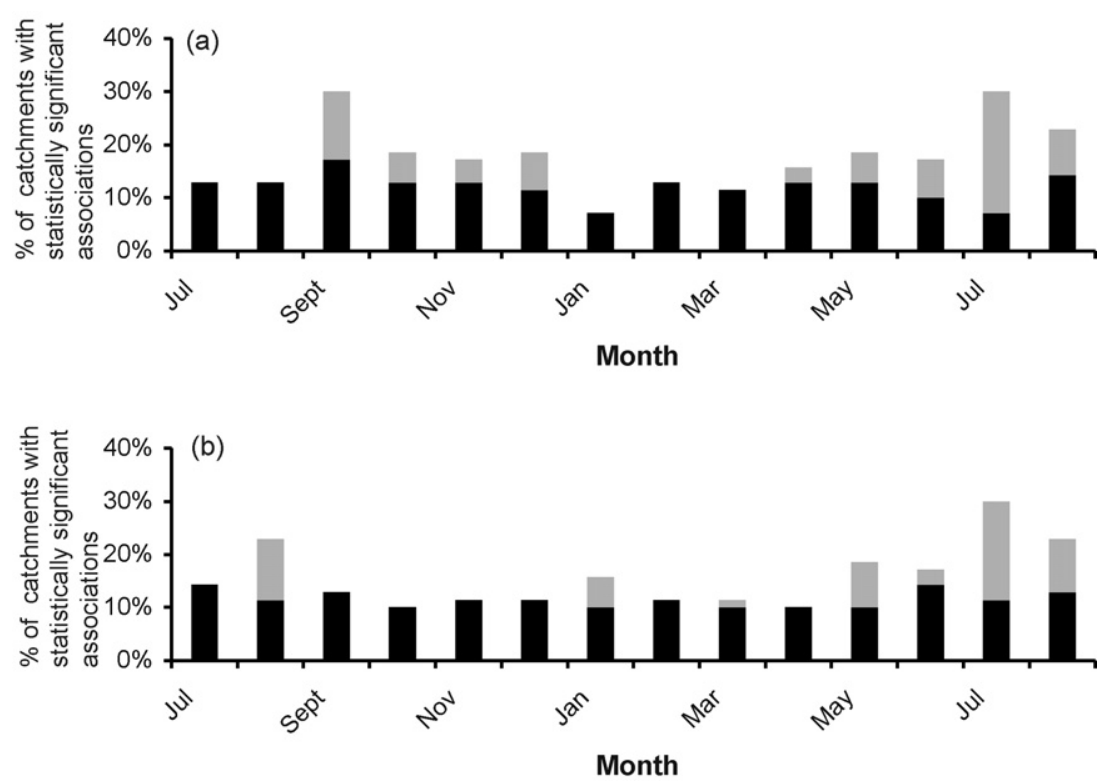

Fig. 3. Summary of the results for the precipitation correlations: (a) percentage of catchments reporting significant positive correlations and (b) percentage of catchments reporting significant negative correlations. Grey bars represent the actual number of catchments reporting significance, black bars represent the threshold required for field significance as determined in the Monte Carlo analysis. 
during the same time. A simple explanation is that the precipitation input into the soil over this time period would be subject to lower evaporation rates, subsequently yielding higher soil moisture amounts in the spring. Spring grasses may then take advantage of that moisture and provide a high quality food source for grasshopper nymphs, although further field-based evidence is required to support this hypothesis.

Both positive and negative significant correlations are observed in late spring-early summer months. Over this time period the precipitation signal may be confounded by many other variables. This result is not unexpected, given that precipitation does not accurately represent the total amount of moisture available at the land surface. In the soil the availability of moisture is controlled through the partitioning of the available precipitation by surface characteristics such as the soil infiltration rates, vegetation amount and type, slope, precipitation rate, and evaporation and transpiration rates. In the late fall and early winter months the relationships between precipitation and subsequent population densities were clearer because much of that precipitation was not leaving the soil via high evapotranspiration rates.

\subsection{Soil moisture-grasshopper population correlations}

Both surface and root zone soil moisture were tested in this procedure, yielding similar results, thus subsequent discussion will focus on the results related to root zone soil moisture estimates. In Fig. 4, the relationships between soil moisture and subsequent populations are clearer than those shown for precipitation (Fig. 3), although the patterns are similar. August of the previous year exhibited a high negative correlation (30\% of catchments). From September through to April, a consistent positive relationship is apparent, with between $18 \%$ and $24 \%$ of catchments reporting a significant positive relationship. Significant negative relationships emerge in December and February, although the reason for the deterioration of the signal during these months is unclear. A strong positive relationship was detected in the summer months (JuneAugust of the current year) with more than $23 \%$ of catchments reporting significant negative correlations.

In contrast to the precipitation correlations, the correlations between mean monthly soil moisture and grasshopper densities in the summer months show a very clear signal. The months of June-August all exhibit significant negative correlations. This suggests that soil moisture during the summer period may be a more explanatory variable than precipitation as soil moisture accounts more specifically for the amount of moisture available in a grasshopper's environment.

\subsection{Results of the chi-squared analysis}

The results of the chi-squared analyses are presented in Fig. 5. Each figure represents a summary of the
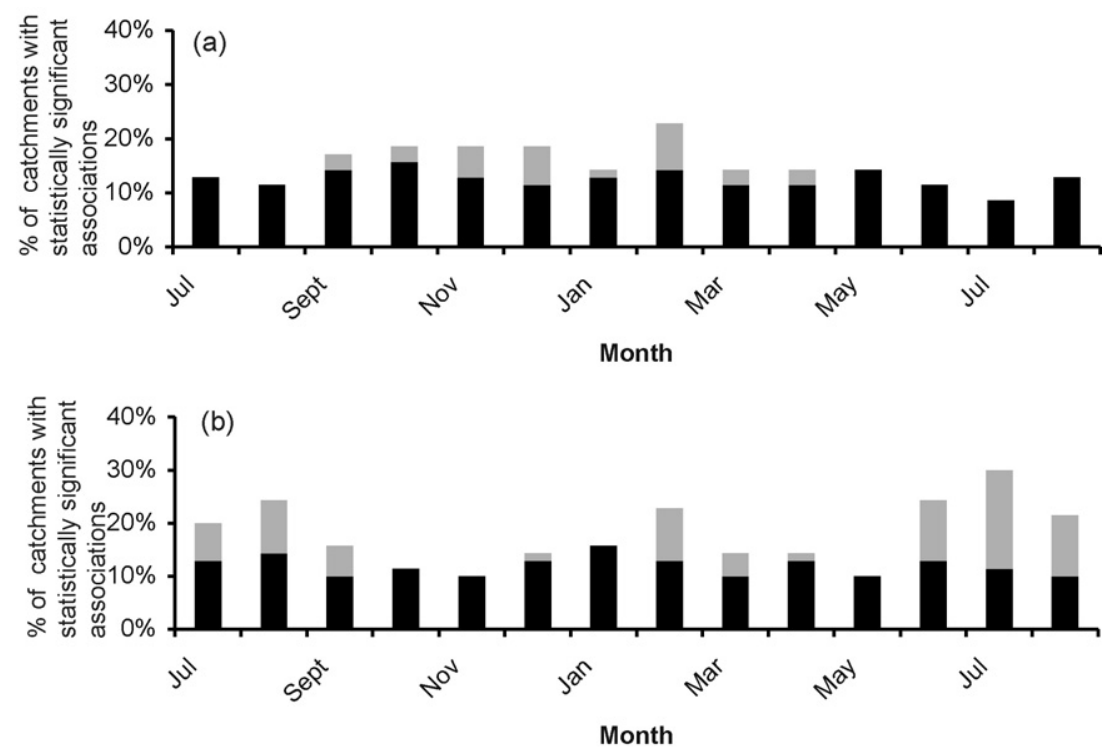

Fig. 4. Summary of the results for the root zone soil moisture correlations: (a) percentage of catchments reporting significant positive correlations and (b) percentage of catchments reporting significant negative correlations. Grey bars represent the actual number of catchments reporting significance, black bars represent the Monte Carlo threshold for field significance. 
(a)

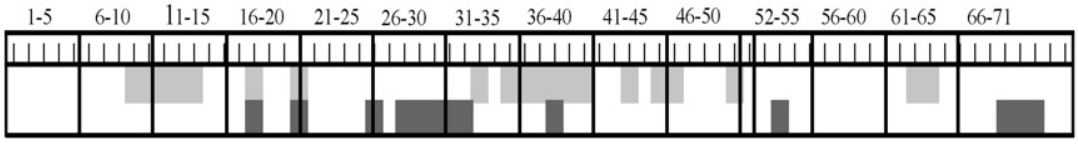

(b)

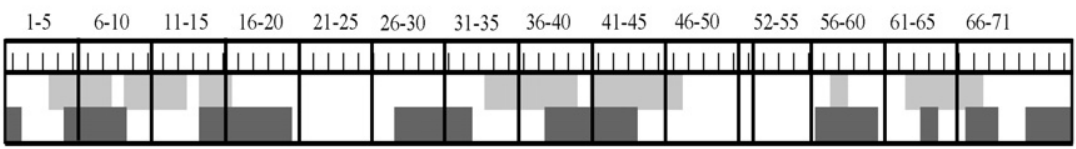

(c)

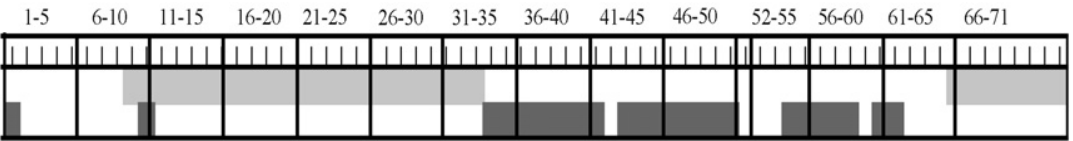

(d)

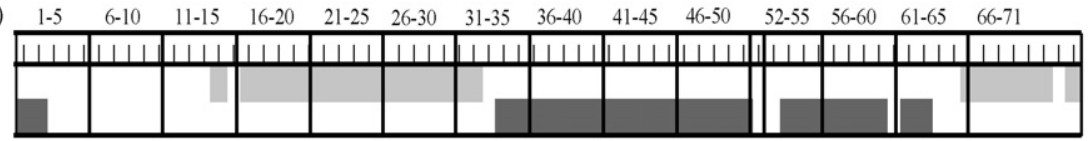

(e)

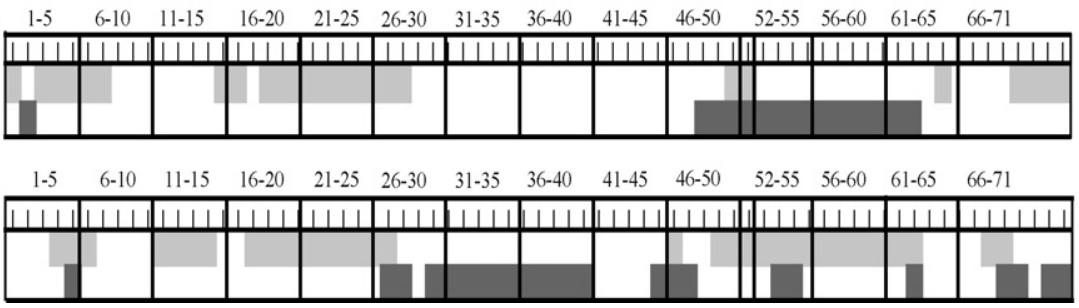

Fig. 5. (a) High grasshopper densities associated with maximum daily temperatures; (b) high grasshopper densities associated with minimum daily temperatures; (c) low densities associated with maximum daily temperatures; (d) low densities associated with minimum daily temperatures; (e) high grasshopper densities associated with soil moisture; (f) low grasshopper densities associated with soil moisture. For figures (a)-(d), grey bars indicate associations with warm conditions; black bars indicate associations with cool conditions. For figures (e) and (f) grey bars indicate associations with high moisture; black bars indicate associations with low moisture. Time shown on the $x$-axis refers to the standardized reference week related to grasshopper development, please see text for more details.

results across all 70 catchments, where the light grey or dark grey bars indicate field significance (a statistically significant number of catchments have statistically significant relationships between the variables in question). The light grey bars indicate an association with warm temperatures (or high soil moisture), and the dark grey bars indicate a statistically significant association with cool temperatures (or low soil moisture). Unlike the results presented for correlations, this technique compares weather conditions between years of high densities and average densities, and between years of low and average densities, therefore the resulting analysis is useful for identifying both the timing and direction (either positive or negative) of the relationship, providing the researcher with an improved understanding of the nature of the linkages between climate and the species population density. In the discussion below the terminology "excess of days" or "deficit of days" is used to indicate where there were more or fewer daily occurrences of the variable in question (maximum/minimum temperature, soil moist- ure) between years of high (low) abundance and years of average abundance. Time shown on the $x$-axis of Fig. 5 is the standardized reference week which was calculated by inputting temperature into growth curves established by Lactin et al. (1995) thus standardizing all catchments to represent phenological development rather than the actual calendar date.

\subsubsection{Temperature and high grasshopper densities}

Statistically significant associations (field significance) between high grasshopper densities and daily maximum temperatures are shown in Fig. 5a. Weeks 914 show an association to high temperatures (excess of days of high maximum temperatures/deficit of days of low maximum temperatures); the relationship changes to one with low temperatures (deficit of days of high maximum temperatures/excess of days of low maximum temperatures) around week 25, and lasts until week 31. After week 31 (corresponding to approximately late January or early February), high densities are associated with warm weather (excess of days of 
high maximum temperatures/deficit of days of low maximum temperatures); this association lasts through to the approximate time of hatch. Following hatch, no definite association exists.

Fig. 5b shows the associations between high grasshopper populations daily minimum temperatures. The early weeks before and during the typical oviposition period (weeks 1-15) show associations to both with both warm and cool temperatures (both excess and deficit of days of high and low minimum temperatures), sometimes during the same week. Weeks 16-32, however, indicate there is an association with cool temperatures (deficit of days of high minimum temperatures/excess of days of low maximum temperatures); similar to the relationships described above for maximum temperatures. The remaining weeks show no discernible patterns.

The lack of a significant association between temperatures and high densities is of interest, as the conventional belief is that outbreaks are associated with warm and dry conditions. The absence of strong relationships in the chi-squared analysis and the contradictory findings (both positive and negative correlations observed) in the correlations suggest that temperature relationships with the overall grasshopper population are heavily modified, particularly at the regional level. This may be evidence that the problem of predicting grasshopper populations is a multivariate one; simply considering each climate variable in isolation explains only a portion of the total variability.

\subsubsection{Temperature and low grasshopper densities}

Associations between low grasshopper densities and daily maximum temperatures are shown in Fig. 5c. The overall pattern is much clearer than those described above for high population densities. The early weeks in the analysis show no definitive associations, with several weeks showing associations with both high and low temperatures. Weeks 10-32 exhibit statistically significant associations with high temperatures (excess of days of high maximum temperatures/deficit of days of low maximum temperatures). At week 33, the relationship abruptly changes, where low population densities are associated with low temperatures, a characteristic evident through the approximate hatch period to week 60 . Weeks $61-71$ see a return to an association with high temperatures.

The associations between low grasshopper populations and daily minimum temperatures (Fig. 5d) have a similar pattern to those described above for maximum temperatures. In weeks 9-32 low densities are associated with high temperatures (excess of days of high minimum temperatures/deficit of days of low minimum temperatures); nearly all of the weeks during this period were found to have statistical significant relationships. From weeks 33 through 62 low temperatures (deficit of days of high minimum temperatures/ excess of days of low minimum temperatures), are associated with low population densities in the summer grasshopper counts. The remaining weeks (63-71) revert to an association with high temperatures (excess of days of high minimum temperatures/deficit of days of low minimum temperatures).

The most striking aspect of the results of the chisquared analysis is the dramatic difference in the strength of the relationships between years of high grasshopper densities (Fig. 5a and b) and years of low densities (Fig. 5c and d). Whereas the analyses of high grasshopper populations shows weak patterns through time, with relationships existing at only certain points for short periods of time (4-6 weeks), the analyses of low grasshopper populations have very clear temporal patterns over significant lengths of time in which a particular relationship prevails. The low density analyses show sharp divisions between three particular regimes of climate-grasshopper associations. The first time period of temporal association begins around week 10 and continues until week 30; during this period low densities are associated with warm weather. This time period corresponds approximately with the late fall to winter months, September-December. At this stage, the embryo has an opportunity to develop in the late fall following oviposition and prior to entering obligate diapause, usually by October (Moore, 1948; Pickford, 1966). The association with warm weather in the late fall is somewhat perplexing because higher temperatures following oviposition implies that the embryos can get a head start on development before entering diapause, which facilitates early hatch. However, the high temperatures persisting into the winter months could indicate that the eggs remain in diapause longer than in average years. Some researchers believe that the egg will terminate diapause after a certain amount of time has passed (Church and Salt, 1952; Pickford, 1966) in which the egg experiences low temperatures. With warmer temperatures, the egg would remain in diapause longer, which may have adverse effects on the embryo, possibly even death (Fisher et al., 1996).

The second general pattern of temporal associations, beginning around week 32 and lasting through the approximate hatch period (week 50) until week 62, associates low densities with low temperatures. This time period corresponds with the late winter to late spring months, or January-June. Low temperatures 
cause the embryo to develop at a slower rate, delaying hatch, at which point the environment is not as suitable for nymphs. Low temperatures after hatch also suggest slower growth rates, leaving nymphs vulnerable to environmental stresses such as disease and predation for longer periods of time.

The third general pattern of temporal associations, associating low densities once again with warm weather, begins around week 60 and proceeds to the end of the study period, week 71 (July and August). At this time, grasshoppers have reached or are approaching adulthood. These results seem counter-intuitive, as warm weather would hasten the growth of nymphs into adults and help ensure the survival of a healthy population.

The results of the correlation analysis and the chisquared analysis are generally in agreement. The correlations in the late fall and early winter months (September-December) showed a significant inverse relationship between temperature and population density, which agrees with the results of the chisquared analyses. The correlations in May and June, the time around the hatch date, also showed an inverse relationship. However, the chi-squared analysis supports the hypothesis of an association between low populations and lower temperatures.

\subsection{Soil moisture: chi-squared analysis}

\subsubsection{High densities}

Fig. 5e shows the associations between high grasshopper densities and estimated root zone soil moisture. Until approximately week 14 , there is no consistent relationship. Around week 14, high grasshopper densities are associated with wet conditions (excess of days of high soil moisture/deficit of days of low soil moisture), which persists until week 25 . Following this time period is a lengthy period of virtually no association until about week 47, after which an association with dry conditions (deficit of days of high soil moisture/excess of days of low soil moisture) is observed through week 61 . A short period where high grasshopper densities are associated with wet soil moisture conditions is observed after week 67 .

\subsubsection{Low densities}

Similar to the results of the chi-squared analysis for temperature, associations between low grasshopper densities (Fig. 5f) and soil moisture are more clearly defined than those shown for high densities (Fig. 5e). Illustrated in Fig. 5f, low grasshopper populations are associated with wet soil moisture conditions in the early weeks (excess of days of high soil moisture/ deficit of days of low soil moisture). This relationship exists intermittently from week 4 to week 26 , at which point a transition occurs towards an association with dry conditions (deficit of days of high soil moisture/excess of days of low soil moisture). This association persists until week 39. These weeks correspond approximately to the early winter months (November and December). As mentioned previously, moisture conditions during this time are often important in determining the moisture conditions in early spring, where high moisture conditions can be quite favourable for young grasshoppers. This result suggests that the reverse is also true, where dry moisture conditions can create poor growth conditions in the spring.

A relationship between wet conditions (excess of days of high soil moisture/deficit of days of low soil moisture) re-emerges around week 48 extending through week 61 , although there are time periods where field significance is observed for both high and low soil moistures, a condition that suggests that extremes in either direction are detrimental. Weeks 45-61 indicate that the association returns to one with high soil moisture. Hatch occurs around week 50 , demonstrating that soil moisture likely plays some role in determining the survival of nymphs. The general belief is that high moisture conditions around hatch reduce grasshopper populations significantly, and these findings appear to support those observations.

Overall, the results from the chi-square analysis for soil moisture agree with those of the correlation analysis. The correlation analyses suggested that an inverse relationship between grasshopper density and soil moisture exists in July and August of the previous year; this result is supported in the chi-squared analysis of low grasshopper densities, which illustrates associations to high soil moisture during the same time period (weeks 1-10). The September-December correlations do not show a strong relationship, but a corresponding time period in the chi-squared analyses of low grasshopper densities, particularly towards November and December (weeks 20-30) do show some associations with dry conditions in the analysis of low densities. The January-April correlations indicate a slight positive relationship. The corresponding time period in the chi-squared analyses (weeks 26-45) shows an association between low densities and dry conditions. The May-August correlations show convincing inverse relationships, which are supported by the chisquared results of both the high and low densities. 


\section{Conclusions}

The results of the chi-squared and correlation analysis suggest that grasshopper population dynamics are strongly associated with climate and weather, visible at the regional scale (defined in this study as stream catchments). However, particularly in the chisquare analysis, the discrepancy between the low and high density analyses suggests that the control over populations is primarily a function of limiting the population as opposed to contributing to an outbreak. This supports the current view of the grasshopper risk forecast as providing the potential for an increase in risk, with subsequent weather determining whether that potential is realized.

The lack of a conclusive association between high densities and warm temperatures or dry conditions suggests that outbreaks can happen even when weather or soil moisture conditions are not much different than in years of average population levels. Instead, cool and wet weather, long believed to reduce grasshopper populations if it occurs around the hatch date, may serve as an important control mechanism. In other years, where weather does not serve to limit grasshoppers, population recruitment is enough to cause an outbreak, given that a female grasshopper can lay hundreds of eggs in a single year (Pickford, 1962, 1966). If the population increases even three- or four-fold in 1 year, it will only take 2 or 3 years to reach severe outbreak conditions. However, if inclement weather strikes at the correct time, the population drops to low levels until successful recruitment allows the population to increase.

Current population models are based primarily on predicting potential densities based on the previous years' population. The models have shown to be successful in predicting population increases, but are inadequate because predictions of potential density cannot predict population crashes. The results of this study support the success of those models in years of population increases where weather appears to be of little consequence. However, these results also address the major weakness of the current forecasts-the inability to predict population decline when future weather reduces survival and development. This study provides a method of improving the forecasts with a scenarios approach.

The general agreement of the results of both the correlations and the iterative chi-squared analysis with previous results at the field scale and in the laboratory show that relationships between grasshopper populations and climate can be detected at the regional scale.
These results also indicate that the prediction of grasshopper populations may be potentially improved upon by including modeled or observed soil moisture and climate information into the prediction equations. However, the relationships between climate and grasshopper populations do not appear to be as strong at the regional scale as has been previously detected in field scale studies. This result is likely due to local scale variability (i.e., spatial heterogeneity) in both grasshopper densities and climate and soil moisture variables that limits the ability of simple statistical analyses to detect the relationships.

\section{Acknowledgements}

This work was supported by the Department of Geography at the University of Guelph and through a grant from the National Sciences and Engineering Research Council of Canada. Luke Powell's thesis work on this topic benefited from discussions with Ze'ev Gedalof.

\section{References}

Berg, A.A., Famiglietti, J.S., Rodell, M., Jambor, U., Holl, S.L., Reichle, R.H., Houser, P.R., 2005. Development of a hydrometeorological forcing data set for global soil moisture estimation. Int. J. Climatol. 25, 1697-1714.

Berg, A.A., Famiglietti, J.S., Walker, J.P., Houser, P.R., 2003. Impact of bias correction to reanalysis products on simulations of North American soil moisture and hydrological fluxes. J. Geophys. Res. 108 (D16), 4490, doi:10.1029/2002JD003334.

Capinera, J.L., Horton, D.R., 1989. Geographic variation in effects of weather on grasshopper infestation. Environ. Entomol. 18 (1), 8-14.

Caprio, J.M., 1966. A statistical procedure for determining the association between weather and non-measurement biological data. Agric. Meteorol. 3, 55-72.

Caprio, J.M., Quamme, H.A., 1999. Weather conditions associated with apple production in the Okanagan Valley of British Columbia. Can. J. Plant Sci. 79, 129-137.

Caprio, J.M., Quamme, H.A., 2002. Weather conditions associated with grape production in the Okanagan Valley of British Columbia and potential impact of climate change. Can. J. Plant Sci. 82, 755-763.

Church, N.S., Salt, R.W., 1952. Some effects of temperature on development and diapause in eggs of Melanoplus bivittatus (Say) (Orthoptera: Acrididae). Can. J. Zool. 30, 173-184.

Coxwell, C.C., Bock, C.E., 1995. Spatial variation in diurnal surface temperatures and the distribution and abundance of an alpine grasshopper. Oecologica 104, 433-439.

Ducharne, A., Koster, R.D., Suarez, M.J., Stieglitz, M., Kumar, P., 2000. A catchment-based approach to modeling land surface processes in a general circulation model 2. Parameter estimation and model demonstration. J. Geophys. Res. 105 (D20) 24, 823824,838 .

Edwards, R.L., 1960. Relationship between grasshopper abundance and weather conditions in Saskatchewan, 1930-1958. Can. Entomol. 92, 619-624. 
Edwards, R.L., 1964. Some ecological factors affecting the grasshopper populations of Western Canada. Can. Entomol. 96, 307-320.

Fielding, D.J., Brusven, M.A., 1990. Historical analysis of grasshopper (Orthoptera: Acrididae) population responses to climate in southern Idaho, 1950-1980. Environ. Entomol. 19 (6), 1786-1791.

Fisher, J.R., 1994. Temperature effect of post-diapause development and survival of embryos of three species of Melanoplus (Orthoptera: Acrididae). Ann. Entomol. Soc. Am. 87 (5), 604-608.

Fisher, J.R., Kemp, W.P., Pierson, F.B., 1996. Aulocara ellioti (Orthoptera: Acrididae): diapause termination, postdiapause development, and prediction of hatch. Environ. Entomol. 25 (5), 1158-1166.

Gage, S.H., Mukerji, M.K., 1977. A perspective of grasshopper population distribution in Saskatchewan and interrelationship with weather. Environ. Entomol. 6 (3), 469-479.

Johnson, D.L., Worobec, A., 1988. Spatial and temporal computer analysis of insects and weather: grasshoppers and rainfall in Alberta. Mem. Entomol. Soc. Can. 146, 33-48.

Johnson, D.L., 1989a. Spatial analysis of the relationship of grasshopper outbreaks to soil classification. In: McDonald, L., Manly, B., Lockwood, J.A., Logan, J. (Eds.), Lecture Notes in Statistics: Estimation and Analysis of Insect Populations. Springer-Verlag, Berlin.

Johnson, D.L., 1989b. Spatial autocorrelation, spatial modelling, and improvements in grasshopper survey methodology. Can. Entomol. 121, 579-588.

Kerr, Y.H., Waldteufel, P., Wigneron, J.P., Martinuzzi, J.M., Font, J., Berger, M., 2001. Soil moisture retrieval from space: The Soil Moisture and Ocean Salinity (SMOS) mission. IEEE Trans. Geosci. Remote Sens. 39, 1729-1735.

Koster, R.D., Suarez, M.J., Ducharne, A., Stieglitz, M., Kumar, P., 2000. A catchment-based approach to modeling land surface processes in a general circulation model 1. Model structure. J. Geophys. Res. 105 (D20) 24, 809-824, 822.

Lactin, D.J., Holliday, N.J., Johnson, D.L., Craigen, R., 1995. Improved rate model of temperature-dependent development by arthropods. Environ. Entomol. 24 (1), 68-75.

Livezey, R.E., Chen, W.Y., 1983. Statistical field significance and its determination by Monte Carlo techniques. Mon. Weather Rev. $111,46-59$.
MacCarthy, H.R., 1956. A ten-year study of the climatology of Melanopus mexicanus mexicanus (Sauss.) (Orthoptera: Acrididae) in Saskatchewan. Can. J. Agric. Sci. 36, 445-462.

McKeown, A.M., Warland, J.S., McDonald, M.R., 2005. Long-term marketable yields of horticultural crops in southern Ontario in relation to seasonal climate. Can. J. Plant Sci. 85, 431-438.

Moore, H.W., 1948. Variations in fall embryological development in three grasshopper species. Can. Entomol. 80, 83-88.

Njoku, E.G., Jackson, T.J., Lakshmi, V., Chan, T.K., Nghiem, S.V., 2003. Soil moisture retrieval from AMSR-E. IEEE Trans. Geosci. Remote Sens. 41, 215-229.

Parker, J.R., 1930. Some effects of temperature and moisture upon Melanoplus mexicanus mexicanus Saussure and Camnula pellucida Scudder (Orthoptera). Montana Agricultural Experiment Station Bulletin 223.

Pickford, R., 1962. Development, survival and reproduction of Melanoplus bilituratus (Wlk.) (Orthoptera: Acrididae) reared on various food plants. Can. Entomol. 94, 859-869.

Pickford, R., 1966. The influence of date of oviposition and climatic conditions on hatching of Camnula pellucida (Scudder) (Orthoptera: Acrididae). Can. Entomol. 98, 1145-1159.

Reichle, R.H., Koster, R.D., Dong, J., Berg, A.A., 2004. On global soil moisture from satellite observations, land surface models, and ground data: implications for data assimilation. J. Hydrometeorol. $5,430-442$.

Schell, S.P., Lockwood, J.A., 1997. Spatial analysis of ecological factors related to rangeland grasshopper (Orthoptera: Acrididae) outbreaks in Wyoming. Environ. Entomol. 26 (6), 1343-1353.

Stinner, R.E., Gutierrez, A.P., Butler Jr., G.D., 1974. An algorithm for temperature-dependent growth rate simulation. Can. Entomol. 106, 519-524.

Uvarov, B., 1966. Grasshoppers and Locusts: A Handbook of General Acridology, vol. 1. The Centre for Overseas Pest Research, London.

Uvarov, B., 1977. Grasshoppers and Locusts: A Handbook of General Acridology, vol. 2. The Centre for Overseas Pest Research, London.

Verdin, K.L., Verdin, J.P., 1999. A topological system for delineation and codification of the Earth's river basins. J. Hydrol. 218, 1-12.

Zimmerman, K.M., Lockwood, J.A., Latchininsky, A.V., 2004. A spatial Markovian model of rangeland grasshopper (Orthoptera: Acrididae) population dynamics: do long-term benefits justify suppression of infestations? Environ. Entomol. 33 (2), 257-266. 